\title{
Urgent need for consensus: international survey of clinical practice exploring use of platinum-etoposide chemotherapy for advanced extra-pulmonary high grade neuroendocrine carcinoma (EP-G3-NEC)
}

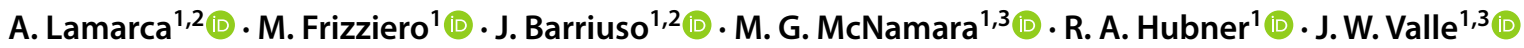

Received: 24 September 2018 / Accepted: 17 November 2018 / Published online: 30 November 2018

(c) The Author(s) 2018

\begin{abstract}
Background Platinum-etoposide (PE) chemotherapy $(\mathrm{CH})$ is a globally established combination for extra-pulmonary high grade neuroendocrine carcinoma (EP-G3-NEC); the optimal schedule has not been established.

Methods An international survey was designed, and completed by clinicians with an expertise in the field to assess consistency in clinical practice.

Results Seventy-five replies were received (June-Nov'17). A minority of physicians (13; 17.6\%) did not take Ki-67 or morphology $(9 ; 12.0 \%)$ into consideration for selection of $\mathrm{CH}$. Most $(72 ; 96.0 \%)$ selected PE-CH as first-line treatment for EP-G3-NEC. CH schedules varied: cisplatin-based $(37 / 71 ; 52.1 \%)$, carboplatin-based (34/71; 47.9\%); intravenous etoposide $(64 / 71 ; 90.1 \%)$, oral etoposide $(7 / 71 ; 9.9 \%)$. Choice of second-line $\mathrm{CH}$ depended on time to progression on PE-based firstline: if $>6$ months, re-challenge with PE was the preferred choice $(34 ; 45.9 \%)$; if $<6$ months, alternative combinations such as fluoropyrimidine/irinotecan $(21 ; 29.2 \%)$ or temozolomide/capecitabine $(22 ; 30.6 \%)$ were used.

Conclusion Significant variation in PE regimen employed exists. Standardising clinical practice would facilitate clinical trial development.
\end{abstract}

Keywords Neuroendocrine $\cdot$ Chemotherapy $\cdot$ High grade $\cdot$ Carcinoma $\cdot$ Practice $\cdot$ Survey

\section{Introduction}

Neuroendocrine neoplasms (NENs) are considered to be rare malignancies, although their incidence has been rising [1]; they are classified according to tumour morphology and proliferation (according to the World Health Organisation (WHO)/European Neuroendocrine Tumor Society (ENETS) guidelines [2]). Morphology is classified

A. Lamarca

angela.lamarca@christie.nhs.uk

$\triangle$ J. W. Valle

juan.valle@christie.nhs.uk

1 Department of Medical Oncology, The Christie NHS Foundation Trust, Manchester M20 4BX, UK

2 Division of Cancer Sciences, University of Manchester, Manchester, UK

3 Division of Cancer Sciences, Manchester Academic Health Science Centre (MAHSC), University of Manchester, Manchester, UK as well- or poorly-differentiated. Proliferation is assessed objectively by Ki-67 index or mitotic count. Malignancies with a Ki-67 index $>20 \%$ are considered high-grade (grade 3) neuroendocrine carcinomas (G3-NEC), when morphology confirms poor differentiation. A subset of G3 tumours (Ki-67> 20\%) show well-differentiated morphology and are known as G3-neuroendocrine tumours (G3-NETs) [3]. Extra-pulmonary G3-NECs (EP-G3-NECs) are usually diagnosed in advanced stages, when only palliative treatment is available $[2,4]$, thus survival is poor (12-17 months) due to their aggressive natural history [3-5].

Platinum-etoposide chemotherapy is the globally-established standard of care for the first-line treatment of patients with advanced EP-G3-NEC, based on the treatment algorithm for its pulmonary counterpart (small cell lung cancer) and on high tumour response rates reported with this combination in a small retrospective study from $1991[6,7]$. This practice has not changed over the last three decades and has never been corroborated by prospective trials. The most updated ENETS guidelines state that "The combination of cisplatin and etoposide, or alternative regimens substituting 
carboplatin for cisplatin or irinotecan for etoposide, are recommended as first-line therapy" [8]. Given these choices, the optimal chemotherapy option for patients with advanced EP-G3-NEC remains controversial and is expected to vary significantly between treating centres and clinicians. Some studies have suggested the potential role of $\mathrm{Ki}-67$ for selection of chemotherapy regimens (higher response to platinum-etoposide chemotherapy for patients with higher Ki-67 $(>55 \%)$ ) [2, 4]. However, this has not been validated in prospective series. Furthermore, although platinum-etoposide chemotherapy is the most commonly used in clinical practice, a number of schedules exist and the most effective schedule/dose/administration route of such combinations has not been established [9, 10].

In addition, a number of retrospective series have reported results of use of multiple chemotherapy regimens (temozolomide-based, taxane-based, 5-fluorouracil- or topotecanbased) after failure of platinum-etoposide therapy in patients with NECs [2]. The most suitable chemotherapy regimen in the second-line setting, therefore, also remains unknown [8]. There is heterogeneity of treatments offered to patients diagnosed with EP-G3-NECs, and so retrospective studies are underpowered and the design of prospective clinical trials is difficult, both in the first- and second-line setting.

\section{Methods}

To clarify current practice in the management of advanced EP-G3-NECs, an international survey was designed to investigate the use of chemotherapy across centres with an expertise in NENs. The survey was circulated and completed by clinicians with an expertise in the field. The aim was to identify which platinum-etoposide chemotherapy schedules were in use across centres, and thereby assess consistency in clinical practice. Duplicate replies from an individual centre were excluded, if these concurred.

\section{Results}

One-hundred and twenty individuals with an expertise in NENs were approached. Seventy-five replies were received (June-November 2017). Surveys were completed by Medical Oncologists ( $n=53 ; 70.7 \%)$, Radiation Oncologists (12; $16.0 \%)$, Gastroenterologists $(8 ; 10.7 \%)$ and Endocrinologists (2; $2.7 \%)$. The United Kingdom was the most represented country ( $n=25$ responses; $33.3 \%$ ), followed by Spain (13; $17.3 \%)$, Italy $(9 ; 12 \%)$, France $(7 ; 9.3 \%)$ and others [Sweden $(2 ; 2.7 \%)$, Netherlands $(2 ; 2.7 \%)$, Greece $(3 ; 4.0 \%)$, Germany $(1 ; 1.3 \%)$, Denmark $(2 ; 2.7 \%)$, Belgium $(1 ; 1.3 \%)$; USA ( 1 ; $1.3 \%)$, others $(8 ; 10.7 \%)]$. Most physicians completing the survey $(40 ; 53.3 \%)$ had $>10$ years of experience in the field and $32(43.20 \%)$ were working in ENETS Centres of Excellence (CoE). A small minority did not take Ki-67 $(n=13$ respondents; $17.6 \%)$ or morphology $(9 ; 12.0 \%)$ into consideration for selection of chemotherapy regimens. Although Ki-67 (using a threshold of 55\%) was considered to be clinically informative for tailoring treatment by $31.1 \%$ of physicians, a significant number of experts $(43.2 \%)$ did not use a Ki-67 cut-off for this purpose; $8.1 \%$ used an alternative cut-off for chemotherapy-related decisions.

Most respondents $(n=72 ; 96.0 \%)$ agreed on selecting platinum-etoposide chemotherapy [cisplatin-based (37/71; $52.1 \%)$ or carboplatin-based $(34 / 71 ; 47.9 \%)]$ as first-line treatment for advanced EP-G3-NEC regardless of differentiation and Ki-67 (Fig. 1), although there was a large number of different platinum-etoposide schedules used (Table 1). When etoposide was used, it was predominantly administered in intravenous vs. oral form $(64 / 71 ; 90.1 \%$ vs. $7 / 71$; $9.9 \%$, respectively). The dose of carboplatin was predominantly at a dose of area under the curve (AUC) of $5(84.3 \%)$; others included AUC 6 (9.8\%), AUC 4 (3.9\%), and "other" (2\%). Chemotherapy was usually administered up to a maximum of 6 cycles $(58 ; 79.5 \%)$.

The choice of second-line chemotherapy depended on time to disease progression after completion of first-line

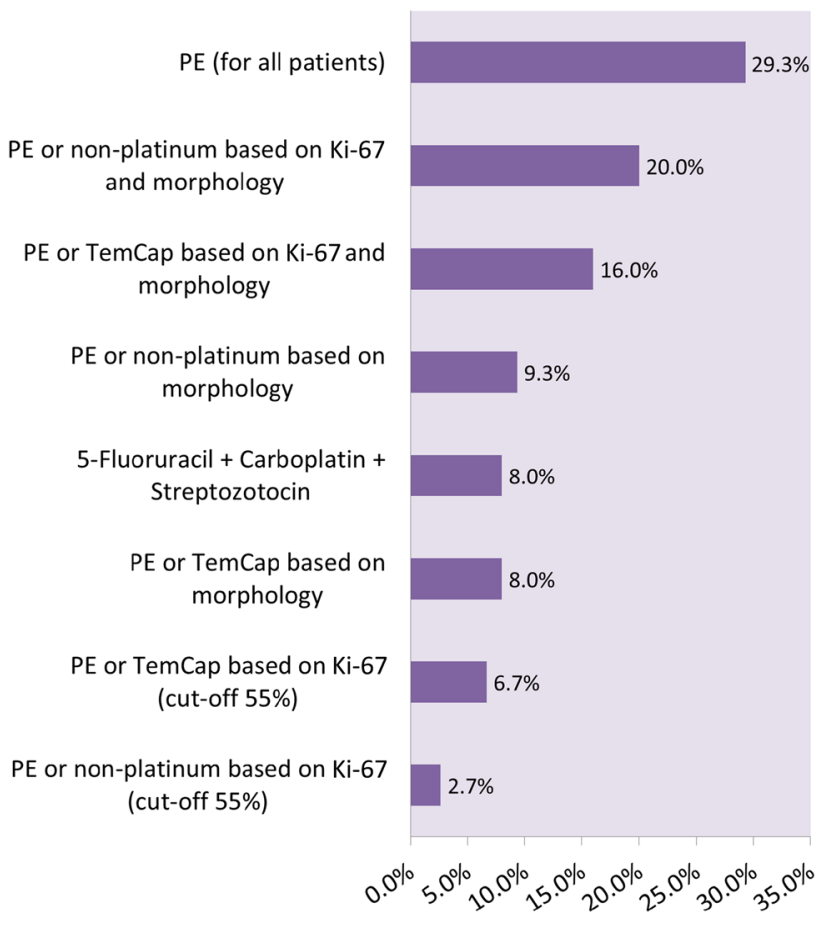

Fig. 1 "What is your choice for first-line chemotherapy in advanced EP-G3-NECs?" The following options received $0 \%$ of the votes: TemCap (for all patients), taxane, cisplatin/irinotecan, 5-fluorouracil \pm oxaliplatin/irinotecan, topotecan. $P E$ platinum-etoposide, TemCap temozolomide capecitabine 
Table 1 When you use platinum-etoposide chemotherapy for the treatment of patients with advanced EP-G3-NEC, which of the following schedules do you use? It is assumed that patient is it (Eastern
Cooperative Oncology Group Performance Status 0-1) for treatment and that renal function is good)

\begin{tabular}{|c|c|c|}
\hline \multirow[t]{2}{*}{ Answer choices } & \multicolumn{2}{|c|}{ Responses } \\
\hline & $\%$ & $n$ \\
\hline 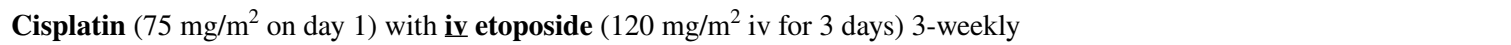 & 2.7 & 2 \\
\hline Cisplatin $\left(100 \mathrm{mg} / \mathrm{m}^{2}\right.$ on day 1$)$ with iv etoposide $\left(120 \mathrm{mg} / \mathrm{m}^{2}\right.$ iv for 3 days $) 3$-weekly & 6.9 & 5 \\
\hline 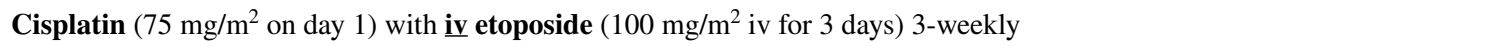 & 23.3 & 17 \\
\hline Cisplatin $\left(100 \mathrm{mg} / \mathrm{m}^{2}\right.$ on day 1$)$ with $\underline{\text { iv }}$ etoposide $\left(100 \mathrm{mg} / \mathrm{m}^{2}\right.$ iv for 3 days $) 3$-weekly & 5.5 & 4 \\
\hline Cisplatin ( $25 \mathrm{mg} / \mathrm{m}^{2}$ on day 1,2 and 3 ) with iv etoposide (100 mg/m iv for 3 days) 3 -weekly & 1.4 & 1 \\
\hline Cisplatin ( $25 \mathrm{mg} / \mathrm{m}^{2}$ on day 1,2 and 3 ) with iv etoposide ( $120 \mathrm{mg} / \mathrm{m}^{2}$ iv for 3 days) 3 -weekly & 2.7 & 2 \\
\hline $\begin{array}{l}\text { Cisplatin }\left(100 \mathrm{mg} / \mathrm{m}^{2} \text { on day } 1\right) \text { with } \underline{\text { iv }} \text { etoposide }\left(100 \mathrm{mg} / \mathrm{m}^{2} \text { iv on day } 1\right) \text { followed by oral etoposide }\left(200 \mathrm{mg} / \mathrm{m}^{2} \text { on days } 2\right. \\
\text { and 3) 3-weekly }\end{array}$ & 2.7 & 2 \\
\hline $\begin{array}{l}\text { Cisplatin }\left(100 \mathrm{mg} / \mathrm{m}^{2} \text { on day } 1\right) \text { with } \underline{\text { iv }} \text { etoposide }\left(100 \mathrm{mg} / \mathrm{m}^{2} \text { iv on day } 1\right) \text { followed by oral etoposide }\left(200 \mathrm{mg} / \mathrm{m}^{2} \text { on days } 2\right. \\
\text { and 3) ever3-weekly }\end{array}$ & 0.0 & 0 \\
\hline Cisplatin $\left(100 \mathrm{mg} / \mathrm{m}^{2}\right.$ on day 1$)$ with oral etoposide $\left(200 \mathrm{mg} / \mathrm{m}^{2}\right.$ on days 1,2 and 3$) 3$-weekly & 1.4 & 1 \\
\hline Carboplatin (AUC details in question 3) with oral etoposide (50 mg bd for 7 days) 4-weekly & 2.7 & 2 \\
\hline Carboplatin (AUC details in question 3 ) with iv etoposide $\left(100 \mathrm{mg} / \mathrm{m}^{2}\right.$ iv for 3 days) 3 -weekly & 20.6 & 15 \\
\hline 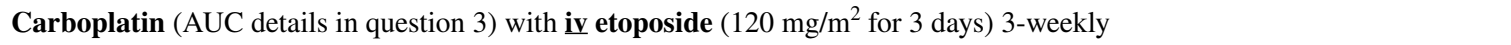 & 1.4 & 1 \\
\hline Carboplatin (AUC details in question 3) with oral etoposide (200 mg/m $\mathrm{m}^{2}$ on days 1,2 and 3) 3-weekly & 5.5 & 4 \\
\hline $\begin{array}{l}\text { Carboplatin (AUC details in question 3) with iv etoposide }\left(100 \mathrm{mg} / \mathrm{m}^{2} \text { iv on day } 1\right) \text { followed by oral etoposide }\left(200 \mathrm{mg} / \mathrm{m}^{2}\right. \\
\text { on days } 2 \text { and 3) 3-weekly }\end{array}$ & 10.9 & 8 \\
\hline $\begin{array}{l}\text { Carboplatin (AUC details in question 3) with iv etoposide }\left(120 \mathrm{mg} / \mathrm{m}^{2} \text { iv on day } 1\right) \text { followed by oral etoposide }\left(200 \mathrm{mg} / \mathrm{m}^{2}\right. \\
\text { on days } 2 \text { and 3) 3-weekly }\end{array}$ & 4.1 & 3 \\
\hline I don't know & 2.7 & 2 \\
\hline Other (please specify) & 5.5 & 4 \\
\hline
\end{tabular}

$i v$ intravenous, $b d$ twice a day, $n$ number, \% percentage —-most common answers are highlighted

platinum-etoposide treatment. When progression was documented after 6 months of completion of first-line treatment, re-challenge with platinum-etoposide was the preferred choice $(34 ; 45.9 \%)$. If progression was documented within 6 months, alternative combinations such as fluoropyrimidine/irinotecan $(21 ; 29.2 \%)$ or temozolomide/capecitabine $(22 ; 30.6 \%)$ were used.

\section{Discussion}

Results from the current survey highlight the challenges for physicians treating EP-G3-NECs, with respect to uncertainty regarding the optimal chemotherapy schedule to use. Even though there is near consensus in the selection of platinumetoposide based chemotherapy for the first-line treatment of patients with advanced EP-G3-NEC, this survey shows the significant heterogeneity and variability in platinum-etoposide regimen use that exists across institutions. Given the difficulties in conducting prospective clinical trials in this setting, a consensus statement establishing recommended regimens and schedule may be warranted to standardise practice and facilitate clinical trial development. However, at present, such advice would not be based on strong levels of evidence (level A/level B) since prospective randomised studies do not exist. There are ongoing trials in the first and second-line settings in this disease group which may inform the community further; treating patients based on decisions from multidisciplinary committees in centres with a clear expertise in NENs is of radical importance until results of such clinical trials are available.

Acknowledgements The authors would like to thank all physicians who kindly completed this survey and UKINETS (UK and Ireland Neuroendocrine Tumour Society) for their support in distributing the survey. Dr Angela Lamarca was part-funded by the ASCO Conquer Cancer Foundation Young Investigator Award and The Christie Charity. Dr Jorge Barriuso was part-funded by the European Neuroendocrine Tumour Society (ENETS) with an ENETS Excellence Academy Fellowship Grant (EEAF).

\section{Compliance with ethical standards}

This work met compliance with ethical standards.

Conflict of interest No conflict of interest to report.

Ethical approval This article does not contain any studies with human participants performed by any of the authors. 
Informed consent For this type of study, formal consent is not required.

Open Access This article is distributed under the terms of the Creative Commons Attribution 4.0 International License (http://creativeco mmons.org/licenses/by/4.0/), which permits unrestricted use, distribution, and reproduction in any medium, provided you give appropriate credit to the original author(s) and the source, provide a link to the Creative Commons license, and indicate if changes were made.

\section{References}

1. Dasari A, Shen C, Halperin D, Zhao B, Zhou S, Xu Y, et al. Trends in the incidence, prevalence, and survival outcomes in patients with neuroendocrine tumors in the United States. JAMA Oncol. 2017;3:1335-42.

2. Sorbye H, Strosberg J, Baudin E, Klimstra DS, Yao JC. Gastroenteropancreatic high-grade neuroendocrine carcinoma. Cancer. 2014;120:2814-23.

3. Heetfeld M, Chougnet CN, Olsen IH, Rinke A, Borbath I, Crespo $\mathrm{G}$, et al. Characteristics and treatment of patients with G3 gastroenteropancreatic neuroendocrine neoplasms. Endocr Relat Cancer. 2015;22:657-64.

4. Sorbye H, Welin S, Langer SW, Vestermark LW, Holt N, Osterlund $\mathrm{P}$, et al. Predictive and prognostic factors for treatment and survival in 305 patients with advanced gastrointestinal neuroendocrine carcinoma (WHO G3): the NORDIC NEC study. Ann Oncol. 2013;24:152-60.
5. Lamarca A, Walter T, Pavel M, Borbath I, Freis P, Nunez B, et al. Design and validation of the GI-NEC score to prognosticate overall survival in patients with high-grade gastrointestinal neuroendocrine carcinomas. J Natl Cancer Inst. 2017;109:djw277.

6. Mitry E, Baudin E, Ducreux M, Sabourin JC, Rufie P, Aparicio T, et al. Treatment of poorly differentiated neuroendocrine tumours with etoposide and cisplatin. Br J Cancer. 1999;81:1351-5.

7. Moertel CG, Kvols LK, O'Connell MJ, Rubin J. Treatment of neuroendocrine carcinomas with combined etoposide and cisplatin. Evidence of major therapeutic activity in the anaplastic variants of these neoplasms. Cancer. 1991;68:227-32.

8. Garcia-Carbonero R, Sorbye H, Baudin E, Raymond E, Wiedenmann B, Niederle B, et al. ENETS consensus guidelines for highgrade gastroenteropancreatic neuroendocrine tumors and neuroendocrine carcinomas. Neuroendocrinology. 2016;103:186-94.

9. Ali AS, Gronberg M, Langer SW, Ladekarl M, Hjortland GO, Vestermark LW, Osterlund P, et al. Intravenous versus oral etoposide: efficacy and correlation to clinical outcome in patients with high-grade metastatic gastroenteropancreatic neuroendocrine neoplasms (WHO G3). Med Oncol. 2018;35:47-1103.

10. Frizziero M, Lamarca A, Kordatou Z, Barriuso J, Nuttall C, McNamara MG, et al. Carboplatin-etoposide chemotherapy (CBET) for patients diagnosed with advanced extra-pulmonary (EP) poorly differentiated (PD) neuroendocrine carcinoma (NEC): findings from a European Neuroendocrine Tumour Society Centre of Excellence [Abstract]. ENETS Annual Meeting (Barcelona, March 2018), Abstract \#2107 2018. 